AROUEOLOGÍA Y SOCIEDAD

№ 28, 2014: 397-406

ISSN: $0254-8062$

\title{
NUEVOS MOVIMIENTOS SOCIALES, POLÍTICA REGIONALY DISCURSO ÉTNICO EN ANGARAES, HUANCAVELICA
}

\author{
ROMMEL PLASENCIA SOTO \\ UnIVERSIDAD NACIONAL MAYOR DE SAN MARCOS \\ PLASENCIASOTO@gmail.com
}

\section{RESUMEN}

Una idea importante en este artículo es el de etnopolítica, es decir cuando un grupo o movimiento piensa que por sus atributos culturales es sujeto de discriminación o cuando utiliza la identidad étnica (un término más restringido que el de cultura) para participar en la competencia política y poder obtener ventajas y recursos de la sociedad. El caso peruano no es una excepción.

PalabRas Clave: Identidad, etnicidad, Huancavelica, movimientos sociales, política regional.

\begin{abstract}
An important item idea is that of ethno-political, when a group or movement thinks its cultural attributes is the subject of discrimination or when using the ethnic identity (a term more restricted than that of culture) to participate in political competition and obtain advantages and resources of society. The Peruvian case is no exception.
\end{abstract}

KEYworDs: Identy, ethnic, Huancavelica, social movements, regional policy.

\section{INTRODUCCIÓN}

Este trabajo de investigación tiene como objetivo entender la dinámica de los nuevos movimientos que participan en las contiendas políticas del departamento de Huancavelica. Estos movimientos en cierto modo independientes de los llamados partidos políticos "tradicionales" tienen en lo fundamental dos características:

1. surgieron más o menos entrado el siglo XXI y

2. aglutinan a las capas medias provincianas y de campesinos comuneros, ampliando de ese modo, el abanico de la participación política a nivel departamental.

En efecto, se ha dicho que a fines de los años 90, se abre una época de decisivos cambios, uno de ellos fue precisamente la aparición de los movimientos de "independientes" formados casi simultáneamente con la demolición institucional del gobierno de Fujimori. Al satanizarse los partidos políticos de base nacional y estos, devorados por sus propias crisis orgánicas; se alentó el surgimiento de estos grupos que tuvieron entre otras razones el de llenar el vacío programático y discursivo con nuevas propuestas. 
El aymarismo, el cusqueñismo (cómo lo amazónico, lo chanka o lo wanka) como discursos ideológicos acompañaron muchas veces a estos movimientos y participaron de los gobiernos regionales y municipales, utilizando símbolos y reminiscencias arqueológicas e históricas, imprimiéndoles ideas de autenticidad y de diferencia cultural.

\section{FUNDAMENTOS TEÓRICOS}

Este fenómeno ha sido evaluado desde dos perspectivas. Para algunos esta eclosión de "independientes" sólo revelaría la fragilidad de nuestras instituciones políticas y de desarticulación social como producto de una etapa posconflicto interno sin resolución, y de formas dictatoriales propias del fujimorismo que condensaron viejas conductas de hacer "política" (por ello es que Carlos Meléndez 2006 los ha llamado "viejos desconocidos").

Para otros, fue más bien el despliegue ciudadano de actores sociales hasta hace poco excluidos y ninguneados (Grompone s/f), como la población rural e "indígena" y "que desafían el lugar de subordinación estructural que padecían desde tiempo atrás” (Escalante 2011: 24)

Sea cual fuere, su importancia es ya determinante, pues con la constitución de los gobiernos regionales en el país, han adquirido un mayor protagonismo y liderazgo. También ha servido (es una hipótesis de trabajo) para dotar de empleo a profesionales de provincias. Esta última afirmación nos remite necesariamente a las dos fuentes de estos movimientos: las bases regionales de algunos partidos "tradicionales" y las ONGs, que transfirieron sus discursos y sus experiencias extraídos de ámbitos rurales y departamentales.

Por eso al amparo de las políticas multiculturales de los gobiernos neoliberales de América Latina en los años 90 (Larrea s/f) y del auge de la cooperación externa para políticas de afirmación cultural, es que estos grupos revindicaron la indianidad, la negritud o la particularidad cultural (como el regreso a las fuentes), obteniendo importantes logros de interlocución y de representación política.

Para comprender mejor este aspecto discutiremos brevemente tres conceptos que son útiles para este trabajo, como son la nueva ruralidad, los nuevos movimientos sociales y la cultura.

\section{LA NUEVA RURALIDAD}

Un intento de comprensión teórica para entender este fenómeno puede ser el de apelar al concepto de "nueva ruralidad", entendida como las nuevas características que van delineando el ámbito rural en países como el Perú. Una de esas características sería la creciente "ruralización" (periurbanización) de las ciudades y la "urbanización" (rurbanización) del campo. Una de sus causas es la nueva performance del capitalismo que no sólo posee un carácter "global" sino que la crisis del viejo modelo industrial ha dado paso a la tercerización y su segmentación.

Este nuevo tipo de capitalismo tiene pues alcance universal pero se ancla en las particularidades locales y regionales, donde globalización y diversificación van de la mano. Antes que un desarrollo lineal e irreversible sería más bien una imbricación con las formas domésticas de producción en los países del hemisferio sur.

Los ámbitos rurales se han acercado a la ciudad como nunca antes. Pero este acercamiento se ha dado básicamente en el terreno del consumo y del capital informacional, pues muchas veces las condiciones técnicas de la producción no han variado por lo menos en un siglo. Aunque en otras regiones el capital de "enclave" o los circuitos de la agricultura de exportación por ejemplo, han producido transformaciones de sus bases productivas a gran escala.

Uno de los cambios importantes y útiles para nuestra investigación, puede ser el surgimiento de nuevas agencias y actores sociales que pueden verse tentados a participar en la política regional, para dotarse de autonomía o aprovechar las fisuras de un sistema político basado en el clientelismo y la “administración étnica”, concepto último al que volveremos más adelante. 


\section{LOS NUEVOS MOVIMIENTOS SOCIALES}

No utilizaremos esta categoría en su acepción clásica surgida en los años 60 y repotenciada en los años 80. Más bien utilizaremos este concepto para explicar los nuevos movimientos políticos de revitalización étnica o cultural surgidos en América Latina en los 90 y de modo particular en los llamados países andinos y entre ellos, el Perú (Plasencia 2010).

Nuestro propósito es pues, comprender aquellas políticas de identidad (entendidas como actores, discursos e imágenes) que politizan lo indígena en el país. Estos procesos de hecho pueden transformar y reinventar las relaciones tradicionales de poder.

En este escenario es que podemos distinguir entre los movimientos etno-políticos y aquellos proyectos que incluyen población campesina. En muchos casos uno puede dar paso al otro, y representan distintos modos de inserción con la población que representan y pautan las estrategias electorales y los imaginarios convocados.

En un trabajo anterior Gunder Frank y Fuentes (1989) desarrollan la idea de que estos "nuevos movimientos sociales" tienen entre otras características su gran "variedad y mutabilidad" y su naturaleza cíclica.

En efecto, muchas de estas agrupaciones en Huancavelica aglutinan no sólo diversas procedencias y formas organizativas muy distintas de los partidos políticos (cerrados, centralizados y reglamentados) sino que se amoldan en base a otras experiencias organizativas (Ongs, Frentes de Defensa, Municipios) con una variedad de discursos y motivaciones: la defensa del medio ambiente, de la organización comunal, la vigencia de la agricultura andina o también como la suma de demandas locales.

Responden también a ciclos políticos (los independientes), económicos (el aumento de recursos económicos regionales) e ideológicos (la afirmación cultural) y que pueden ser de mediano y corto plazo. Estos últimos pueden ser las propias dinámicas regionales. Muchos de ellos han dejado de existir, otros se revitalizan en periodos electorales o simplemente se solapan para ocultar intereses y propuestas contrarias a la misma lógica de estos movimientos, pues el uso de la cultura o la identidad ayudan a disfrazarlos.

Aunque aquí la cuestión es si todos estos fenómenos construyen relaciones igualitarias o crean nuevas formas de dominación o reinventan las ya existentes. Más aún si la contextualización del presente trabajo nos conduce a un departamento como Huancavelica en donde sus bases políticas tradicionales (lo que Andrés Guerrero ha llamado la administración étnica del poder) se fueron erosionando desde los años 70.

\section{CULTURA, IDENTIDAD Y ETNICIDAD ${ }^{1}$}

Planteamos que cuando un grupo exige derechos o algún tipo de ventajas apelando a sus atributos culturales es porque cree que por su utillaje cultural está en una posición vulnerable, posiblemente exista una identidad étnica.

Las posturas pos-barthianas (Bauman 2001, Comaroff y Comaroff 2011) superan los tradicionales usos culturalistas de las identidades, para poner el énfasis en las capacidades de negociación y de utilización política de los marcadores culturales en contextos plurales.

Insisten en que los grupos ya no se definen por límites precisos, así estos sean producto de relaciones interétnicas; sino que más bien al estar insertados en conjuntos mayores (el "Estado-Nación") es que despliegan su distintividad sólo cuando compiten por los recursos disponibles en la sociedad.

1 "En este contexto, el término cultura no tiene el sentido de la antropología sino que se refiere a esa noción que reivindican quienes pretender afirmar una subjetividad colectiva objetivándola para el mercado" (Comaroff y Comaroff 2011: 37). 
Sin embargo, han sido Brubaker y Cooper (2000) quienes han precisado que la cultura es lo "fundamental" y lo "general", y que sólo ciertos rasgos culturales (que suelen ser llamados en este proceso como étnicos) pueden ser activados y utilizados por ejemplo para reclutar militantes.

De igual modo es importante distinguir las nociones de "etnicidad" e "identidad étnica", la primera -tan amplia como la cultura- sería la conciencia en sí, y la segunda más restringida, sería afín a la de conciencia para sí. ${ }^{2}$ Solo la última moviliza y hace circular sentimientos de pertenencia, en donde los escenarios de pugna pueden ser el de obtener ventajas económicas, acciones de reconocimiento y sobre todo participar en política, para probar de ese modo sus niveles de autonomía.

\section{El CONTEXTO}

El departamento de Huancavelica es uno de los más económicamente deprimidos del Perú, ostenta los niveles más altos de pobreza y de pobreza extrema. Si bien esta última ha descendido en los últimos años, un 70\% de su población sigue siendo considerada pobre. Las actividades agropecuarias y la minería siguen siendo los rubros más importantes de su economía, representando ambas el 68.5\% de la PEA para el 2011. La primera actividad está asociada a la subsistencia y emplea a más de la mitad de su población departamental; la segunda está vinculada a los mercados exteriores y tiene aún en la actualidad, poco impacto en los ingresos departamentales.

Según el INEI, para el 2013 la población rural representaría el 77,8\% el más alto a nivel nacional y el $57,2 \%$ de su población censada habla o tiene como lengua materna al quechua. Posee además 88 municipios distritales y 183 comunidades campesinas.

Para el 2007 Huancavelica poseía 3 veces más el porcentaje nacional de analfabetos, es decir un $20,1 \%$ y de los cuales el 76,6\% eran mujeres. Para el mismo censo, Angaraes reportaba un 25,7\% de analfabetos y su población rural triplicaba a la urbana.

Estos estándares creemos que se deben no sólo al rol depreciado del espacio andino en la economía nacional, sino también a una cultura de la sujeción, es decir, de escasa ciudadanía. Un escenario que fue el legado del sistema de haciendas tradicionales y de sus constelaciones locales del poder (Plasencia 1997).

Tampoco olvidemos que fue este departamento uno de los más severamente afectados por el ciclo de violencia política de los 80 y 90. Por ejemplo en un rápido conteo (Escalante 2011:58) de 684 actos de violencia política, 247 ocurrieron en la provincia de Huancavelica y 186 en Angaraes, ocupando estos, los dos primeros lugares.

\section{LA PEQUEÑA SUIZA O CAMPO-MINA}

Angaraes es una de las 7 provincias de Huancavelica, representa el 12 por ciento de la población total departamental. En ella están instalada la compañía minera Buenaventura desde los inicios de su formación como empresa. Sus comunidades son las instituciones más importantes en el control y uso de los recursos agropecuarios de la provincia. Posee 12 distritos y 81 comunidades campesinas reconocidas. Incluso la capital provincial, una vieja ciudad de estirpe colonial, que alberga anexos que juntos conforman la comunidad de San Juan de Dios de Lircay.

En 2010 La población de la provincia era de 55, 704 habitantes y la de los electores 30,183 de los cuales el 52,2\% eran mujeres. Según la cifras del JNE entre los procesos electores del 2006 y el 2010 hubo altos índices de fragmentación y volatilidad electoral. En el nivel distrital había una gran dis-

2 Trasladándonos al lenguaje económico, la cultura sería cómo un valor de uso y la etnicidad, un valor de cambio. Es decir el portafolio cultural es amplio y se usa cotidianamente, en cambio la etnicidad posee un rasgo distintivo y sólo adquiere valor y sentido cuando entra en un campo de relaciones, comparaciones y confrontaciones. 
persión de la población electoral por ejemplo, en Huayllay Grande en el 2010 existían 934 electores, pero en Anchonga eran 1,825.

$\begin{array}{cr}\text { ANGARAES: ACTOS DE VIOLENCIA POLÍT } \\ \text { Anchonga } & 23 \\ \text { Antaparco } & 4 \\ \text { Ccochaccasa } & 7 \\ \text { Chincho } & 20 \\ \text { Congalla } & 14 \\ \text { Huanca Huanca } & 3 \\ \text { Julcamarca } & 51 \\ \text { Lircay } & 15 \\ \text { Secclla } & 21 \\ \text { S.Tomás de Pata } & 28 \\ \text { TOTAL } & \mathbf{1 8 6}\end{array}$

\section{LA INSTANCIA ETNO-POLÍTICA}

En los inicios del siglo XXI se constituyeron agrupaciones o movimientos políticos que incorporaron en sus programas y plataformas de acción el tema cultural o étnico, muchas veces asociados a la revalorización de la agricultura, el turismo y la conservación de los recursos naturales como programas de acción. ${ }^{3}$

El esplendor de estos se debe fundamentalmente a las políticas de descentralización local que fueron implementándose desde los años 80 y cuyo auge puede establecerse en el gobierno de Alejandro Toledo, en donde además se implementaron políticas crecientes de participación ciudadana.

Luego, los crecientes fondos de inversión otorgados a los municipios del país como al FONCOMUN y la implementación del canon, convirtieron a las municipalidades en instituciones centrales de esta nueva dinámica.

Creemos que todas estas medidas importantes tuvieron como lejano antecedente a la reforma agraria de los 70 que transformó para siempre el campo peruano. En la provincia de Angaraes se distinguen claramente, dos periodos de actuación de estos movimientos:

a. de 1995 al 2006 es el periodo de actuación electoral del MINCAP e Inti,

b. del 2006 hacia adelante el de Ayni y Ayllu.

Uno de los primeros grupos en constituirse fue el MINCAP (Movimiento Independiente de Campesinos y Profesionales) fundado en Lircay en 1992, y que ha colocado tres alcaldes provinciales y que fue participante en los procesos electorales del 2003 y 2007. ${ }^{4} \mathrm{Si}$ bien en su programa no menciona lo étnico-cultural de forma específica, durante el ejercicio de Raúl Anyaipoma Bendezú, se privilegiaron la recuperación de las fiestas lirqueñas y la generalización de la palabra Anqara.

Este hecho pudo haber influido para que la socióloga Anahí Durand la calificase cómo una "revalorización étnica" (2006), aunque quizás haya sido sólo un intento de revitalizar tradiciones culturales de la esfera misti.

3 Sólo para mencionarlo como un ejemplo departamental, en el 2006 aparece en Huancavelica la agrupación denominada Movimiento Descentralista Popular Rikcharisum Llaqta Yuyacjchanakunapaq, que en las elecciones del 2010 quedó en quinto lugar y logró colocar dos alcaldes distritales, en Acoria y Mariscal Cáceres respectivamente. El auge de los medios de comunicación y la creciente migración pendular, explicarían este auge de nuevas capas de comuneros-profesionales.

4 Si bien MINCAP se fundaría en 1992, su gestación procede del periodo de 1987 a 1992, cuando Fujimori reorganiza el sector público y los profesionales echados o renunciantes se dedicaron a realizar proyectos particulares o para FONCODES, esto les daría la oportunidad de re-conectarse con el mundo rural y de especializarse en proyectos de infraestructura. 


\section{EL MINCAP}

Raúl Anyaipoma es un ingeniero mecánico de profesión y nació en Lircay, representa a las capas medias de esta ciudad con una fuerte vocación tecnocrática.

Sin embargo, este alcalde sería uno de los protagonistas de la profunda escisión que se produjo en MINCAP, en donde los "técnicos" excluyen y separan a los "étnicos", descalificando a los campesinos como interlocutores y como agentes. Esta nueva diferenciación se basaría "ya no en la propiedad de la tierra sino en su nivel de instrucción" (Durand 2006:565) en que la condición de profesional universitaria suplantaría a la del antiguo misti. ${ }^{5}$

Por ejemplo en una entrevista hecha a Raúl Anyaipoma en octubre del 2013, luego de una apasionada remembranza del "mundo anqara", admite la dificultad de planificar el desarrollo en las comunidades de la zona pues "los pueblos están aislados y no han logrado nuclearse". Para el ex -alcalde un rasgo organizacional propio se convierte entonces en una rémora para el desarrollo, en su afirmación, se mezclan vívidamente el desarrollismo con ciertos prejuicios mistis.

La redes del MINCAP estaban afirmadas en la comunidad de San Juan de Dios de Lircay que lo conforma una constelación de pueblos (Carhuapata, Constancia, Allato, Palcas-Cascabamba y Uchcubamba) que rodean a la capital provincial y que en promedio, tienen mejores servicios básicos que están ausentes muchas veces, en aquellas más lejanas y que colindan por ejemplo con el departamento de Ayacucho.

La movilidad pendular entre Lircay y esas comunidades, contribuyeron a su politización, y fueron un factor decisivo para intentar su autonomía política y alterar la "administración étnica" del poder en manos de los vecinos de la capital. En esta labor ayudaron muchos maestros activistas del Sutep y que si bien eran oriundos de lircay, pertenecían a sus "clases medias" y "populares" que residían en barrios como Buenavista y Pueblo Nuevo en Lircay.

\section{INTI}

El Movimiento Regional Independiente INTI, ha participado en los procesos del 2006 y 2010, con relativa fortuna. Tuvo en una oportunidad la alcaldía provincial con Javier Ravelo Chávez natural de Ayaccocha (distrito de Salcabamba en Tayacaja), quien construyó su discurso desarrollista en base a su experiencia como agrónomo formado en la Universidad Nacional Agraria de La Molina -donde se adhirió a las enseñanzas de Juan Zapater, una especie de pionero de la "agricultura orgánica"- y el de haber compartido el utillaje conceptual del PRATEC.

Cuando trabajó en la microrregión de Angaraes ayudó a fundar en dicha provincia en 1989, la agrupación política de Cambio 90, por su cercanía profesional con Fujimori, quien había sido docente en la Universidad Nacional Agraria. Dicha afiliación duraría hasta 1996 (Javier Ravelo entrevista personal, 2014).

INTI retuvo algunas alcaldías distritales en Tayacaja y Julcamarca en donde obtuvo casi el 25\% de los votos provinciales. El énfasis puesto en su gobierno municipal fue el de pasar del "puro cemento" al de los proyectos productivos y con participación comunal. Si bien esto causaría algún malestar entre la población urbana de la capital provincial, permitió no sólo el protagonismo rural sino también, la conjunción de visiones del desarrollo realizadas por los municipios y las ONGs.

Ravelo poseía paralelamente a su ejercicio edil, la organización no gubernamental de desarrollo Sicra (creada en 1997), que desarrollaba sus proyectos en comunidades cercanas a la ciudad y que constituyeron desde un inicio sus bases de apoyo como Llumchi, Chahuarma, Ahuay y Jatunpata.

5 Con el creciente avance de la economía mercantil en los Andes, los mistis no sólo han perdido poder sino que enfrentan nuevos retos y actores inéditos. Acertadamente el antropólogo Juan Ossio menciona que para Andamarca (en el sur de Ayacucho) "no hay mínima evidencia de que (los mistis) se constituyen en fuentes normativas de los indígenas, ni que sean los únicos responsables de la circulación de la riqueza, ni mucho menos, que los indígenas se enfrenten entre sí, compitiendo por sus favores" (1978:6) 
Este campo de poder significaba que la esfera de la promoción del desarrollo se convertía luego en relaciones políticas. ${ }^{6}$ Tanto Julián Zorrilla (primer alcalde de INTI) como Raúl Anyaipoma y Javier Ravelo, provienen de la "microrregión" antigua oficina de promoción del desarrollo, que a pesar de depender administrativamente de la administración regional, tuvo el rango de organismo descentralizado y con plena autonomía en sus gastos de inversión.

Esta ventaja viene por lo menos del primer gobierno de Alan García, quien diseñó la estrategia de micro-regionalización en el llamado "trapecio andino" y que situaba a Angaraes con las provincias en "emergencia económica y social”. Lo revelador fue que desde sus oficinas se adiestraron tres futuros alcaldes. ${ }^{7}$

\section{El CASO DEL ANTROPÓLOGO EN ACCIÓN}

Finalmente a Jatary Ayllu -hoy simplemente Ayllu- formado por el antropólogo Eduardo Candiotti Munarriz fue formado sobre la base de la ONG Yapuq Proder y que fuera dirigida por el propio Candiotti.

Eduardo Candiotti ${ }^{8}$ cursó estudios de antropología en la Universidad Nacional del Centro del Perú (UNCP) a mediados de los años 80 , y se destacó por su habilidad en las relaciones interpersonales. En esas aulas fue en cierto modo influido por Juan José García Miranda, ex profesor de la Universidad de Huamanga, que trasmitía con entusiasmo no solo el legado académico de Efraín Morote sino también, algunas de sus ideas políticas.

García Miranda además poseía un discurso que hoy podemos denominar de "andinista" (García 1996) y que con los años se ha ido perfilando con mayor precisión y mucho de ese ideario, es decir: esencialismo + proyecto político, pudo haber influido en la labor profesional de Candiotti.

Esta agrupación se dio "en un contexto de creciente revalorización étnica, promovida por intelectuales urbanos, activistas políticos y ONGs como el PRATEC u Oxfam América" (Escalante 2012:25). Ayllu según Escalante estaría existiendo gracias a esa "red política" hilvanada por la Ong Yapuq Poder y el movimiento "etno-político" (son las palabras de Escalante) del Consejo Unitario de la Nación Anqara (CUNAN).

Sobre la primera organización Yapuq Proder, es una escisión de PRODER una organización no gubernamental fundada en Huancayo a inicios de los 90. Sus planes de trabajo giraron alrededor del desarrollo rural y la capacitación campesina para una región con relativo desarrollo como es el valle del Mantaro.

A raíz de algunas desavenencias con sus directivos es que Eduardo Candiotti es invitado a "retirarse" de PRODER, este último sale con una cartera de proyectos y de contactos con financieras europeas y se establece en Anchonga, una comunidad campesina cercana a Lircay y cuna de sus ancestros.

Es por esa razón que el apoyo inicial a sus labor política lo obtuvo de comunidades cercanas a Anchonga ${ }^{9}$ en que era relativamente fácil construir redes de lealtad; algo similar a lo hecho por Javier Ravelo, en donde el binomio política local/ONG, les concedía bases sociales de apoyo.

6 No es casual pues que en la provincia, Balvino Zevallos de Campesinos al poder dirigiese la organización no gubernamental Perqa y Eduardo Candiotti, Yapuq Proder.

7 La agrupación Catarisum Llaccta Angaraes Llicclla, constituida en 1985 por un ex militante de Acción Popular perduró hasta 1995, obtuvo el quinto lugar con casi el 11\% de los votos provinciales. Que en el 2006 haya existido un grupo con un nombre similar en las elecciones regionales, nos permite hablar políticamente de "vientres de alquiler".

8 Una reciente tesis de licenciatura (Escalante 2011), trata sobre "un dirigente político de Angaraes", pese a que el tesista no lo nombra para preservar su anonimato a petición del informante, es innegable que se trata Eduardo Candiotti. Su entusiasmo por haber dado información al tesista, contrasta con su negativa en concedernos una entrevista para esta investigación.

9 Entre ellas están Tuco, Rantay, Parco, Chontacancha, Occo y sobre todo la "comunidad piloto" de Ocopa en la que Yapuq Proder construye una piscigranja como parte de un proyecto "cosmogónico", no obstante ser una comunidad de reciente creación, con poca población y casi integrada a la ciudad de Lircay. 
La constitución de la Escuela Rural de Afirmación Andina (ERA) creada a semejanza de muchas instituciones de capacitación rural, fue importante pues no sólo permitió la creación de cuadros y militantes (en que la elección sustituía la escasez de esencia étnica), sino que concientizó a un número importante de sus dirigentes que incluso, ante el giro caudillista de Candiotti, estos siguieron fieles a sus propuestas etno-políticas de base comunal. Lo reconocen Durand (2006), Escalante (2011) y uno de sus protagonistas principales:

Parafraseando a Golte (1987) se podría afirmar que dicha actuación sería una especie de "manejo paralelo de ciclos políticos y laborales" que se traducía en un cuidadoso portafolio de lealtades, compromisos y en especial de capital político de mediano plazo en beneficio del líder.

Arrojada a la arena política, la agrupación de Candiotti pierde tres veces consecutivas la alcaldía provincial (en el 2002, 2006 y 2010). Escalante en un artículo publicado en una revista estudiantil (2012), es más enfático sobre este dirigente y se distancia en algo, del tono apologético que tiene a ratos, su tesis de licenciatura.

En él, menciona que fue finalmente un "movimiento caudillista" y que justo cuando decrecen los fondos externos para su institución de desarrollo, es que tambalean sus alianzas y se precipita su deslegitimación "moral".

Esto último ocurre cuando en el 2010 se alía con el MINCAP para postular al gobierno edil pasando en esa decisión, por encima de sus bases comuneras. Hoy en noviembre del 2013, ocupa el cargo de gerente de desarrollo social del Gobierno Regional de Huancavelica.

El haber aceptado un cargo burocrático que antes censuraba, se deba quizás a que sin apoyo rural de envergadura y sin recursos financieros, la legitimidad que otorga el aparato estatal sea su única alternativa para re-engancharse con algunas comunidades de la región y sobre todo con el movimiento político del actual Presidente Regional (Movimiento Independiente Trabajando para Todos) ${ }^{10}$, para tentar-acaso por última vez- la siempre anhelada representación política.

Sobre la segunda organización vinculada a Eduardo Candiotti el CUNAN, fue gestada como un movimiento etno-político a semejanza del aymarismo o el Frente Popular Yapanchik de Andhuaylas, que reconoce en su filiación ideológica a movimientos más amplios e integrados como los de Bolivia y Ecuador.

Sin embargo sus orígenes vienen del CONAPA (Comisión Nacional de Pueblos Andinos, Amazónicos y Afroperuanos), cuando fue nombrado representante de la etnia anqara en dicha entidad gracias a la propuesta de Juan Ossio, en ese entonces asesor de Eliane Karp. Según Ramón Pajuelo la experiencia del CONAPA sólo "incluyó como una minoría a los dirigentes indígenas, manteniendo una forma organizativa que quedaba completamente en manos de las decisiones personales de Karp, por estar conformada mayoritariamente por asesores estatales y asesores nombrados por ella" $(2006: 75)^{11}$

El CUNAN y Candiotti - son intercambiables- poseen el discurso más radical de los movimientos que estamos reseñando, quizás lo fantasmal de su constitución hace que su coherencia ideológica revierta el páramo de su organización.

10 El Presidente Regional Maciste Díaz Abad es natural de Tayacaja y fue gobernador de Fujimori en 1996, alcalde por su provincia con Vamos Vecino en 1998 y reelegido en el 2002 con Renacimiento Andino, agrupación del notario salcabambino Ciro Gálvez.

No obstante algunos reveses políticos como el de una asonada en la ciudad de Huancavelica en el 2011, por la creación de la universidad de Tayacaja; se ha mantenido estable gracias a su política redistributiva con fondos públicos cada vez más crecientes. Su sinuosidad política, su necesidad de apoyo rural específico y su precario esencialismo andino aprendido de Ciro Gálvez (2003), quizás hayan galvanizado su confianza en Eduardo Candiotti.

11 En el 2002 la COPPIP (Congreso de la Conferencia Permanente de Pueblos Indígenas del Perú) que apoyaba al CONAPA se dividió, un parte importante cuestionó no sólo el manejo personalista de esa institución sino también la poca transparencia en el uso de los fondos externos que recibía. Sin embargo, Candiotti siguió leal al toledismo hasta el término de su gobierno. 
Nos presenta un modelo de sociedad local de pequeña escala, autárquica y solidaria y empeñada en "descolonizar los andes". Predica un esencialismo cultural basado en las características de la sociedad anqara, es decir, una comunidad solidaria y emparentada, en donde el campo (y la agricultura campesina) son vistos como terapéuticos y purificadores, donde la tecnología es eficiente y ancestral.

Mucho de la esfera ritual convocada como soporte discursivo se basa en la experiencia concreta de Yapuq Proder: usos agrícolas, festividades, danzantes de tijeras, la lengua materna y el aprecio por la familia doméstica provienen de la vida cotidiana de las comunidades y de las aldeas que estuvieron en la órbita de su labor de activismo y promoción.

\section{CONCLUSIONES PROVISORIAS}

Estas agrupaciones y movimientos políticos nos pueden aproximar a nuevas identidades "étnicas" y regionales, o quizás no. Sus contenidos discursivos (palabras e imágenes) han ido insertando en la política regional un nuevo componente: los contenidos culturales.

Estos contenidos tienen como referencia la existencia de la llamada "cultura anqara" que parece ser un grupo de raíz chanca que ocupó entre otros, el actual departamento de Huancavelica en el llamado horizonte tardío (1000-1,500 d.n.e) (Gonzales Carré 1992).

Sus restos arqueológicos diseminados por la provincia dan la certeza de su existencia, el arraigo del quechua y la presencia de comunidades campesinas ancestrales verifican y re-inventan esa herencia cultural en el presente, pues de ellos se ha extraído los insumos del discurso.

Sin embargo, sus líderes poseen formación universitaria, todos vienen de alguna experiencia en la ejecución de proyectos en la provincia, ya sea de organismos públicos o de ONGs, que los han adiestrado en sus relaciones con la población rural y en atender sus demandas. Aunque hay que reconocer que aspectos centrales de revitalización cultural como la educación bilingüe o la incorporación de propuestas comuneras están ausentes y opacadas por opciones vinculadas a la infraestructura urbana.

Finalmente, esa certeza de originalidad cultural es constantemente re-inventada y re-valorada y su fuerza no sólo radica en sus niveles de veracidad sino, en la incorporación por parte de los profesionales urbanos para legitimarse políticamente y que los utilizan como mecanismos de presión en dos sentidos y equidistantes en su campo de juego: por un lado arremeten contra los funcionarios centralistas y políticos limeños y del otro, se mimetizan en el discurso y en el gesto, con el electorado rural.

Aunque esto no es nuevo, tiene sus antecedentes en el paternalismo indigenista de la primera mitad del siglo XX, y que fue re-utilizado por "independientes" cómo Fujimori, Toledo o Federico Salas, donde el atuendo y las reminiscencias de lo andino reemplazó al compromiso político efectivo (entendido como asignación del poder).

Finalmente, el discurso étnico del que echaron mano posee tres momentos claramente distinguibles (Escalante (2011) los llama acertadamente "vetas discursivas):

a. la primera se basa en los aportes etnohistóricos sobre los anqaras y que es utilizado por los profesionales urbanos de Lircay y Julcamarca, a quienes les resulta atractivo el término de "señorío anqara" pues les evoca las jerarquías como un sistema ordenador,

b. el concepto del etno-desarrollo que fue transitando del desarrollo rural integrado al desarrollo campesino en su propios términos y al que se adscribieron organizaciones como Sicra o Vecinos Perú, y que fue compartido por agrónomos y comuneros establecidos cerca de la capital provincial y,

c. la etno-política, que Candiotti expresa con cálculo y que es patente del caudillo y de los comuneros con conciencia para sí, es decir con opciones étnicas voluntaristas y cuestionadoras.

\section{BiBLIOGRAFÍA}

\section{BAUMAN, Gerd}

2001 "El enigma multicultural: un replanteamiento de las identidades nacionales, étnicas y religiosas" Barcelona: Paidós. 
BRUBAKER Rogers y COOPER Frederick

2000 "Beyond Identy" en www.sscnet.ucla.edu./soc/faculty/brubaker/publications/18_Beyond_Identy.pdf

CEPLAN

2011 “Perú, Síntesis Regional: recursos, potencialidades y crecimiento”, Lima.

COMAROFF Jhon L. y COMAROFF Jean

2011 "Etnicidad S.A." Buenos Aires: Katz.

DURAND, Anahí

2006 "Revalorización étnica y representación política: los casos de Inti y Mincap de Lircay, Huancavelica" en Perú: El problema Agrario en Debate, SEPIA XI, Lima: SEPIA/Oxfam/CIES: 541-581.

ESCALANTE SOLANO, Esteban

2011 "Legitimidad política y liderazgo: el caso de un líder político en la provincia de Angaraes, Huancavelica" tesis para optar el título de Licenciado en Antropología, PUCP.

ESCALANTE SOLANO

2012 "Angaraes: más allá de las otras formas de entender el desarrollo" en LA COLMENA, revista de sociología 5(5): 22-31.

FRANK GUNDER André y Marta FUENTES

1989 "Diez tesis acerca de los movimientos sociales" en REVISTA MEXICANA DE SOCIOLOGÍA, 51 (4), octubre-diciembre.

GÁLVEZ, Ciro

2003 "Predicciones del Renacimiento Andino: Pachacutiy Unanchaykuna" Huancayo: s/e.

GARCÍA MIRANDA, Juan José

1996 "Racionalidad de la cosmovisión andina" Lima: CONCYTEC.

GONZALES CARRÉ, Enrique

1992 “Los Señoríos Chankas” Ayacucho: UNSCH.

GOLTE Jurgen

1987 "La racionalidad de la organización andina" Lima: IEP.

GROMPONE, Romeo

s/f "La creciente vigencia de movimientos y partidos regionales: sus alcances y límites" Lima: JNE.

GUERRERO, Andrés

1993 "De sujetos indios a ciudadanos étnicos: de la manifestación de 1961 al levantamiento indígena de 1990" en VV.AA "Democracia, etnicidad y movimiento indígena: ¿Una nueva política de administración de poblaciones?", Lima: IEP/IFEA.

JURADO NACIONAL DE ELECCIONES (JNE)

"Mapa político electoral del Perú: infob.gob.pe. Versión digital.

LARREA MALDONADO, Fernando

s/f "Estado neoliberal y movimiento indígena: ¿Una nueva política de administración de poblaciones?" en www.alasru.org

MELENDEZ, Carlos

2006 "Los movimientos regionales: los "viejos desconocidos": las elecciones regionales del 2006 y la trivialización el análisis político" en COYUNTURA, enero-febrero: 11-14.

OSSIO, Juan

1978 "Relaciones interétnicas y verticalidad en los Andes" en DEBATES EN ANTROPOLOGÍA, (2):1-23.

PAJUELO, Ramón

2006 "Participación política indígena en la sierra peruana: una aproximación desde las dinámicas nacionales y locales" Lima: Konrad Adenauer/IEP.

PLASENCIA, Rommel

1997 "Conflictos en la sociedad regional: Angaraes 1896-1950" en ANTHROPOLOGICA (15): 135-150.

2010 “Las ciencias sociales y el tema étnico en el Perú" en CULTURA SUR (1) 1:60-66. 